\title{
Practice Parameter: Diagnostic assessment of the child with status epilepticus (an evidence-based review) Report of the Quality Standards Subcommittee of the American Academy of Neurology and the Practice Committee of the Child Neurology Society
}

\author{
J.J. Riviello, Jr., MD; S. Ashwal, MD; D. Hirtz, MD; T. Glauser, MD; K. Ballaban-Gil, MD; K. Kelley, MD; \\ L.D. Morton, MD; S. Phillips, MD; E. Sloan, MD; and S. Shinnar, MD, PhD
}

\begin{abstract}
Objective: To review evidence on the assessment of the child with status epilepticus (SE). Methods: Relevant literature were reviewed, abstracted, and classified. When data were missing, a minimum diagnostic yield was calculated. Recommendations were based on a four-tiered scheme of evidence classification. Results: Laboratory studies $\left(\mathrm{Na}^{++}\right.$or other electrolytes, $\mathrm{Ca}^{++}$, glucose) were abnormal in approximately $6 \%$ and are generally ordered as routine practice. When blood or spinal fluid cultures were done on these children, blood cultures were abnormal in at least $2.5 \%$ and a CNS infection was found in at least $12.8 \%$. When antiepileptic drug (AED) levels were ordered in known epileptic children already taking AEDs, the levels were low in 32\%. A total of 3.6\% of children had evidence of ingestion. When studies for inborn errors of metabolism were done, an abnormality was found in 4.2\%. Epileptiform abnormalities occurred in $43 \%$ of EEGs of children with SE and helped determine the nature and location of precipitating electroconvulsive events $(8 \%$ generalized, $16 \%$ focal, and 19\% both). Abnormalities on neuroimaging studies that may explain the etiology of SE were found in at least $8 \%$ of children. Recommendations: Although common clinical practice is that blood cultures and lumbar puncture are obtained if there is a clinical suspicion of a systemic or CNS infection, there are insufficient data to support or refute recommendations as to whether blood cultures or lumbar puncture should be done on a routine basis in children in whom there is no clinical suspicion of a systemic or CNS infection (Level U). AED levels should be considered when a child with treated epilepsy develops SE (Level B). Toxicology studies and metabolic studies for inborn errors of metabolism may be considered in children with SE when there are clinical indicators for concern or when the initial evaluation reveals no etiology (Level C). An EEG may be considered in a child with SE as it may be helpful in determining whether there are focal or generalized epileptiform abnormalities that may guide further testing for the etiology of SE, when there is a suspicion of pseudostatus epilepticus (nonepileptic SE), or nonconvulsive SE, and may guide treatment (Level C). Neuroimaging may be considered after the child with SE has been stabilized if there are clinical indications or if the etiology is unknown (Level C). There is insufficient evidence to support or refute routine neuroimaging in a child presenting with SE (Level U).
\end{abstract}

NEUROLOGY 2006;67:1542-1550

Endorsed by the American College of Emergency Physicians on August 31, 2006; by the American Academy of Pediatrics on October 3, 2006; and by the American Epilepsy Society on October 3, 2006.

From the Division of Epilepsy and Clinical Neurophysiology and the Critical Care Neurology Service (J.J.R.), Department of Neurology, Children's Hospital, Boston, and Harvard Medical School, MA; Division of Child Neurology (S.A.), Department of Pediatrics, Loma Linda University School of Medicine, CA, CNS representative to the Quality Standards Committee; National Institute of Neurological Disorders and Stroke (D.H.), NIH, Bethesda, MD, CNS representative to the Quality Standards Committee; Comprehensive Epilepsy Center (T.G.), Children's Medical Center, Cincinnati, OH, representative of the Epilepsy Foundation of America; Albert Einstein College of Medicine (K.B.-G.), Bronx, NY, representative of the American Epilepsy Society; Children's Memorial Hospital and Northwestern Medical School (K.K.), Chicago, IL, representative of the American Epilepsy Society; Division of Child Neurology (L.D.M.), Virginia Commonwealth University, Richmond, representative of the Child Neurology Society; Children's Hospital of Orange County (S.P.), CA, representative of the American Academy of Pediatrics; Department of Emergency Medicine (E.S.), University of Illinois at Chicago School of Medicine, representative of the American College of Emergency Physicians; Departments of Neurology and Pediatrics (S.S.), Comprehensive Epilepsy Management Center, Montefiore Medical Center, Albert Einstein College of Medicine, Bronx, NY.

Received March 28, 2006. Accepted in final form August 4, 2006.

Approved by the Quality Standards Subcommittee on January 28, 2006; by the Practice Committee on August 5, 2006; and by the AAN Board of Directors on August 17, 2006.

Address correspondence and reprint requests to American Academy of Neurology, 1080 Montreal Avenue, St. Paul, MN 55116; e-mail: guidelines@aan.com

1542 Copyright (0) 2006 by AAN Enterprises, Inc. 
Table 1 Classification of status epilepticus (SE)

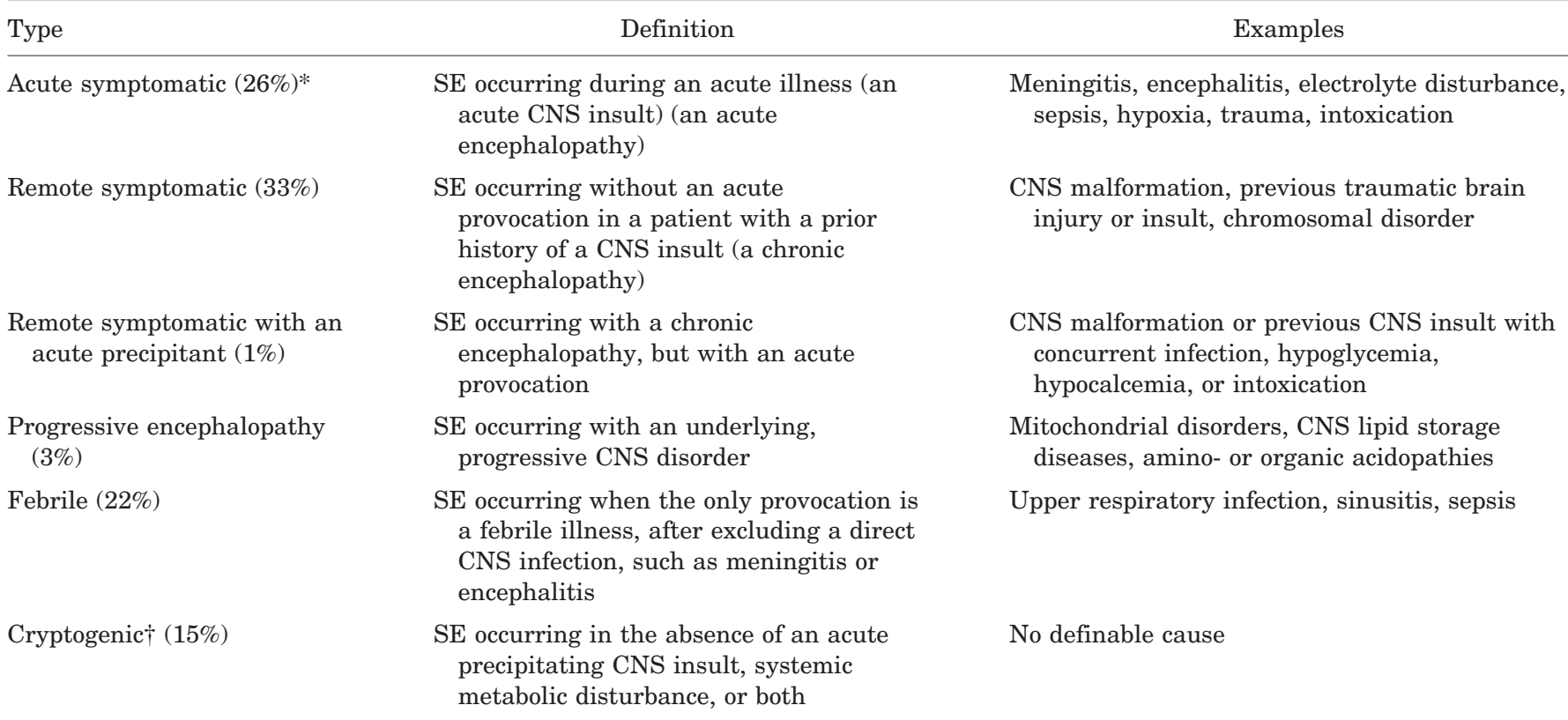

\footnotetext{
* Data for percentages for each group are presented in more detail in appendix 4.

$\dagger$ The category cryptogenic is now used instead of idiopathic, which had been used in the original classification.
}

Status epilepticus (SE) in children, as in adults, is a life-threatening emergency that requires prompt recognition and immediate treatment. Although various definitions of SE have been used since 1983, the most commonly accepted is a 30-minute duration of seizures based on previous studies that found evidence of brain injury in adult monkeys after 45 to 60 minutes of continuous seizures. ${ }^{1-3}$ This 30 -minute definition was adopted in subsequent studies of SE and by the working group on SE of the Epilepsy Foundation of America, ${ }^{4,5}$ This definition also includes two or more sequential seizures without full recovery of consciousness between seizures. ${ }^{5}$

$\mathrm{SE}$ is classified by seizure type and etiology. ${ }^{6,7}$ The seizure type is determined by the origin of the epileptic discharge (i.e., focal or generalized) or if insufficient information is available, indeterminate or unclassifiable. ${ }^{8-10}$ As defined in table 1 , the etiologic classification of SE includes 1) acute symptomatic, 2) remote symptomatic, 3) remote symptomatic with an acute precipitant, 4) progressive encephalopathy, 5) febrile, and 6) cryptogenic (idiopathic).,4,11,12 When some of these studies were done the term idiopathic was used for episodes now called cryptogenic. The category idiopathic is now reserved for the genetically determined epilepsies. ${ }^{13}$ Remote symptomatic with an acute precipitant refers to SE in a child with a prior known diagnosis of epilepsy.

The incidence of SE in children ranges from 10 to 58 per 100,000 per year for children ages 1 to 19

Additional material related to this article can be found on the Neurology Web site. Go to www.neurology.org and scroll down the Table of Contents for the November 14 issue to find the title link for this article. years (mean 38.8 and median 43.8/100,000/year; 95\% CI 18.2 to $59.5 / 100,000 /$ year) or would be 31,600 (range 7,300 to 41,600 ) children under age 18 years in the United States per year. ${ }^{14-17}$ A higher incidence has been reported in infants younger than 1 year of age in two studies (135.2/100,000/year and 156/ 100,000 /year). ${ }^{14,16} \mathrm{SE}$ is a common occurrence in children with epilepsy, ranging from $9.1 \%$ to $27 \%$ over time. ${ }^{18-20}$ SE may also be the presenting manifestation of epilepsy. Symptomatic SE is common in infants and younger children. In one study of 394 children aged 1 month to 16 years, more than $80 \%$ of children less than 2 years of age had acute symptomatic SE, febrile SE, or a progressive encephalopathy whereas cryptogenic and remote symptomatic SE was more common in children older than 4 years. ${ }^{21}$ $\mathrm{SE}$ has been reported to recur in $17 \%$ of children. ${ }^{22}$

Guidelines for AED treatment have been developed for pediatric $\mathrm{SE},{ }^{23-25}$ but specific pediatric guidelines have not been developed for its diagnostic evaluation. The 1993 recommendations of the Epilepsy Foundation of America (EFA) Working Group on Treatment of Convulsive SE included adults and children. ${ }^{5}$ These recommendations, including a treatment sequence with antiepileptic drugs (AEDs), were consensus, rather than evidence-based, and are currently under revision including redefining the duration considered necessary to diagnose SE.

These guidelines recommended a Dextrostix level in all patients with SE, noting that hypoglycemia rarely caused SE, but is obtained to avoid a glucose infusion, and recommended consideration on an individual basis of other diagnostic studies including a complete blood count (CBC), serum chemistries (glucose, sodium, calcium, magnesium, and BUN), AED 
levels, and urine and blood toxicology studies. A lumbar puncture (LP) was recommended when fever occurred with SE, especially in young children, unless a contraindication to LP was present.

This Practice Parameter reviews available evidence concerning the value of diagnostic testing in children and adolescents with SE and provides recommendations based upon this evidence. Treatment guidelines are not included but are under development.

Description of process. We performed a literature search through the library of the University of Minnesota, and MEDLINE, for English-language articles from 1970 to 2005 and yielded 1,609 articles. The search terms were as follows: status epilepticus and, children and, MRI, cranial CT scan, lumbar puncture, spinal tap, electrolytes, metabolic studies, inborn errors of metabolism, EEG, hyponatremia, hypokalemia, hypocalcemia, hypoglycemia, acidosis, alkalosis, azotemia, hypophosphatemia, hypomagnesemia, pleocytosis, toxicology, intoxication. Seizures occurring in neonates less than 1 month of age were excluded, as these are defined as neonatal seizures and are different in cause and prognosis. The upper age limit was 19 years. Only articles reporting studies with more than 20 patients were included in this review. Articles consisting of single patient case reports or small samples of unusual pathologic findings, that would have biased the analysis, or articles that referred specifically to febrile or refractory SE, were excluded. Febrile SE and refractory SE were excluded because each is a selected population. Twenty-five articles were identified and reviewed for preparation of this Parameter. Relevant position papers from professional organizations were also reviewed.

Individual committee members reviewed titles and abstracts for content and relevance. Those papers dealing with diagnostic assessments of SE were selected for further detailed review. Bibliographies of the articles cited were checked for additional pertinent references. Each of the selected articles was reviewed, abstracted, and classified by at least two committee members. Abstracted data included the number of patients, total episodes of SE (if given), ages, nature of subject selection, case-finding methods (prospective, retrospective, or referral), inclusion and exclusion criteria, classification, etiology, and the results of laboratory, EEG, or neuroimaging tests. A four-tiered classification scheme for determining the validity of studies on yield of established diagnostic and screening tests developed by the Quality Standards Subcommittee was utilized as part of this assessment (appendix 2). Depending on the strength of this evidence, it was decided whether specific recommendations could be made, and if so, the level of strength of these recommendations (appendix 3). Evidence pertinent to each diagnostic test together with the committee's evidence-based recommendations is presented.
Recommendations included in this Parameter were based on review of data regarding the following tests for children presenting in SE: 1) blood culture and LP studies; 2) AED levels; 3) toxicology screening; 4) metabolic and genetic studies; 5) EEG; and 6) neuroimaging including CT and MRI.

Most available literature did not specify whether the diagnostic tests analyzed were uniformly applied during each SE episode. Therefore, where reported data were missing, we calculated a minimum diagnostic yield for each test by dividing the total number of positive diagnostic tests reported by the total number of reported SE episodes from each study (therefore assuming that each diagnostic test was performed for each episode of SE, likely leading to an underestimate of the true diagnostic yield of these tests).

It is now common practice to obtain a $\mathrm{CBC}$ and chemistry profiles routinely in children presenting with SE. Thus, we did not develop evidence-based recommendations for these tests but did include in appendix 4 a summary of previous studies regarding their diagnostic yield. Electrolyte (e.g., $\mathrm{Na}^{++}$or other electrolytes, $\mathrm{Ca}^{++}$, glucose) abnormalities or basic metabolic disorders were reported in an average of $6 \%$ (range 1 to $16 \%$ ) of children with SE. In most studies these abnormalities were listed as the etiology. However, it was unclear whether these abnormalities were responsible for the episode of $\mathrm{SE}$ and if correction resulted in cessation of SE.

Analysis of the evidence. In 2,093 children from 20 class III studies, SE was attributed to an acute symptomatic cause in $26 \%$, a remote symptomatic cause in $33 \%$, a remote symptomatic with an acute precipitant in $1 \%$, a progressive encephalopathy in $3 \%$, febrile $\mathrm{SE}$ in $22 \%$, and cryptogenic in $15 \%$ (table 1).

Laboratory studies. Should blood cultures and LP be routinely done in children with SE? Infectious or inflammatory disorders may cause seizures by direct involvement of the CNS, such as with meningitis or encephalitis, or by systemic involvement affecting the brain (i.e., acute symptomatic SE). Systemic illness may aggravate pre-existing epilepsy by lowering the seizure threshold. An infectious disorder may be included in the differential diagnosis if fever is present or if there has been a history of fever or preceding illness. Common clinical practice is that blood cultures are obtained if there is a clinical suspicion of an infection and likewise LP is done when there are clinical features suggestive of CNS infection, especially if fever is present.

Blood cultures (evidence). In six class III studies that reported the category sepsis, with a total of 357 children, blood cultures were reported as positive in $2.5 \pm 0.9 \%$ (range 0.01 to $3.8 \%$; median $2.6 \%$; $95 \%$ CI $1.7 \%$ to $3.3 \%){ }^{33-35,37,38,40}$ This is a minimum yield based on the assumption that blood cultures were done in all patients with SE whether or not sepsis was suspected. Data were not available to determine 
the rate of positive blood cultures in patients in whom sepsis was suspected. Likewise, data were not available to ascertain the incidence of positive blood cultures in those patients clinically considered not to be at risk for infection.

$L P$ (evidence). A documented CNS infection was reported on average in $12.8 \pm 6.2 \%$ (range 3.4 to $26.1 \%$; median $11.5 \%$; $95 \%$ CI $9.9 \%$ to $15.6 \%$ ) of the 1,859 children in the class III studies listed in appendix 4 , but the criteria for obtaining a LP, and the actual number done, is not known. Again, this may represent a lower rate of positive studies than if we knew the actual number of LPs done. In addition, if some patients who did not undergo LP had CNS infection, this also would have raised the diagnostic yield. The variability in range may be related to age, with a higher incidence of CNS infections occurring in the younger children, or to selection criteria. ${ }^{29,30,33,39,41}$

A class III study of 49 children with convulsive SE identified 24 children with SE and fever and in this group bacterial meningitis was detected in 4 of 9 children who had a LP done (8\% of entire group and $17 \%$ of febrile group). ${ }^{44}$ None of the 25 children without febrile SE were diagnosed with meningitis. The etiology of CNS infection in these studies was based on author assignment of diagnosis rather than on the reported confirmatory laboratory test results and included bacterial meningitis in $4.8 \%$ and encephalitis in $3.0 \%$ of children. In three Class III studies ( $\mathrm{n}=$ 185), ${ }^{29,31,40}$ the following diagnoses were documented with LP results: meningitis (14\%), ${ }^{29,31}$ encephalitis $(11 \%),{ }^{29}$ leukemic meningitis $(1 \%),{ }^{29}$ vasculitis $(0.5 \%),{ }^{31}$ and shunted hydrocephalus $(0.5 \%){ }^{29,31} \mathrm{In}$ $3 \%$ of these children, pleocytosis of undetermined etiology was found and suggested that the episode of SE itself was the presumed cause of the pleocytosis. ${ }^{31}$

Conclusions. Data from six class III studies revealed a minimum diagnostic yield of a positive blood culture in $2.5 \%$ of children with SE. Data based on the 1,859 children from the studies listed in appendix 4 revealed that the frequency of diagnosed CNS infection rate was $12.8 \%$. In all of these studies there was no indication that tests were done routinely on all children with SE; it was either stated or presumed that the tests were done selectively.

Recommendations. 1. There are insufficient data to support or refute whether blood cultures should be done on a routine basis in children in whom there is no clinical suspicion of infection (Level U).

2. There are insufficient data to support or refute whether LP should be done on a routine basis in children in whom there is no clinical suspicion of a CNS infection (Level U).

Should AED levels be routinely obtained in children taking AEDs who develop SE? If a child with epilepsy treated with AEDs develops SE, it is possible that AED levels are low, because either there had been a therapeutic response at that level or because
Table 2 Results of studies in which AED levels were obtained*

\begin{tabular}{lrrccc}
\hline $\begin{array}{l}\text { Reference } \\
\text { no. }\end{array}$ & Class & N & $\begin{array}{c}\text { Low AED } \\
\text { levels }\end{array}$ & $\begin{array}{c}\text { AED } \\
\text { withdrawn } \\
\text { or D/C }\end{array}$ & $\begin{array}{c}\text { AED } \\
\text { noncompliance }\end{array}$ \\
\hline 45 & II & 51 & $9 \dagger$ & - & - \\
4 & III & 193 & - & 4 & - \\
34 & III & 83 & - & 23 & - \\
31 & III & 60 & 32 & - & - \\
38 & III & 37 & 1 & - & 1 \\
27 & III & 43 & 27 & - & - \\
39 & III & 37 & - & 3 & - \\
42 & III & 24 & 5 & 1 & - \\
Total & & 528 & 74 & 31 & $1(0.2 \%)$ \\
Mean, \% & & & $32 \pm 25$ & $9 \pm 10$ & - \\
Median, \% & & & 21 & 4.2 & - \\
Range, \% & & & $2.7-63$ & $1-28$ & - \\
$95 \%$ CI, \% & & & $8.8-51$ & $-0.5-18.6$ &
\end{tabular}

\footnotetext{
* Numbers in columns indicate the number of patients in each study who had an abnormal laboratory value for that test. All studies were class III. Fields marked with - indicates that there was no diagnostic category in that individual study for the column entry.

$\dagger$ Total number of abnormalities for each test given with percentage of total abnormalities discontinued (D/C).

$\ddagger$ Four acutely withdrawn in $<1$ week.

$\mathrm{AED}=$ antiepileptic drugs.
}

of inadequate dosing, noncompliance, or withdrawal of the AED.

Evidence. We assumed that AED levels were obtained in those children who were supposed to be on AEDs rather than on all children presenting in SE. One article addressing this question was considered class II. ${ }^{45}$ Data on AED levels were available for review in 528 children in SE from nine studies (table 2 ). AED levels were low in $32 \% \pm 25 \%$ (range 2.7 to $63 \%$; median $21 \%$; $95 \%$ CI $8.8 \%$ to $51 \%$ ) of those children already on AEDs; they had been withdrawn on average in $9 \% \pm 10 \%$ (range $1 \%$ to $28 \%$; median $4.2 \%$; $95 \%$ CI $-0.5 \%$ to $18.6 \%$ ) and patients were noncompliant in $0.2 \%$ overall $(2.7 \%$ when specifically mentioned as a category). Noncompliance was determined by clinical history. In one study it was reported that 4 of the 9 children with low levels had the AED acutely withdrawn or discontinued within 1 week. However, the low AED levels reported in these studies were not necessarily the cause of SE. ${ }^{7,27,45}$

Conclusions. Class II data showed low AED levels in $32 \%$ of children on AEDs, although this was not necessarily the cause of the SE.

Recommendation. AED levels should be considered when a child with epilepsy on AED prophylaxis develops SE (Level B, class II and III evidence).

Should toxicology testing be routinely ordered in children with SE? Ingestion of a toxin or drug abuse are possible etiologies of SE that require very prompt diagnosis and treatment. 
Evidence. A toxic ingestion was documented in $3.6 \%$ (range 1.5 to $5.3 \%$; median $3.8 \%$; $95 \%$ CI $2.3 \%$ to $6.8 \%$ ) of 1,221 children enrolled in 11 class III studies. 4,26,27,29-32,36,37,41,43 The specific toxins were theophylline, lindane, carbamazepine, or chemotherapy. This represents a minimum rate as we used as the denominator all patients in the studies. There is no information on whether toxicology testing was performed based on suggestive history or physical examination findings or because initial screening laboratory studies were negative. A routine urine toxicology screen identifies only drugs of abuse and specific serum toxicology levels are needed to identify specific toxins.

Conclusions. Data from 11 class III studies of children with SE revealed a diagnosis of ingestion in $3.6 \%$. It is not known what proportion of these ingestions was suspected. We deemed this yield high enough to consider testing with specific serum toxicology levels, if indicated, since establishing the diagnosis is critical to treatment.

Recommendation. 1. Toxicology testing may be considered in children with SE, when no apparent etiology is immediately identified, as the frequency of ingestion as a diagnosis was at least 3.6\% (Level $\mathrm{C}$, class III evidence). To detect a specific ingestion, suspected because of the clinical history, it should be noted that a specific serum toxicology level is required, rather than simply urine toxicology screening.

Metabolic and genetic testing. Should testing for inborn errors of metabolism or genetic (chromosomal or molecular) studies be routinely ordered in children with SE? Inborn errors of metabolism (IEM) and specific chromosomal or genetic disorders may cause neurologic dysfunction and epilepsy. In some patients, seizures may worsen during an intercurrent illness or because of metabolic stress. Historic features suggestive of a metabolic disorder are unexplained neonatal encephalopathy; unexplained developmental delay, especially when there is a neurologic deterioration during an acute illness; unusual odors to the urine; unexplained acidosis or coma, especially with recurrent episodes of intolerance to certain foods; the need to eat frequently to prevent lethargy; or episodes of dehydration disproportionate to fluid loss during an illness. The major conditions that are considered to be IEMs include disorders of amino acid, ammonia, and organic acid metabolism, and disorders affecting mitochondrial and peroxisomal functions.

Evidence. Of 735 children in nine class III studies, $\overline{4,29,30,32,34,35}, 39,41,42$ an IEM was diagnosed or present in $4.2 \%$ of children (range 1.2 to $8.3 \%$; median $4.0 \%$; 95\% CI $2.9 \%$ to $5.8 \%$ ) based on a denominator of all children in these studies, although it is likely that testing was done selectively. When specified, pyridoxine dependency, Leigh's disease, neuronal ceroid lipofuscinosis, and a mitochondrial disorder were each found in $0.3 \%$, and Alper's disease, methylmalonic acidemia, and carnitine deficency in $0.2 \%$ each.
Data on chromosomal or genetic disorders are not separately available.

Conclusions. Data from nine class III studies revealed that an IEM was diagnosed in approximately $4 \%$ of children in these studies with SE.

Recommendations. 1. Studies for inborn errors of metabolism may be considered when the initial evaluation reveals no etiology, especially if there is a preceding history suggestive of a metabolic disorder (Level C, class III evidence). The specific studies obtained are dependent on the history and the clinical examination. There is insufficient evidence to support or refute whether such studies should be done routinely (Level U).

2. There are insufficient data to support or refute whether genetic testing (chromosomal or molecular studies) should be done routinely in children with $\mathrm{SE}$ (Level U).

Electroencephalography. Should an EEG be routinely performed in the evaluation of a child with SE? SE is classified as generalized or focal convulsive SE or nonconvulsive SE (NCSE), and the clinical manifestations are associated with electrographic SE. EEG may be needed to demonstrate focality and because the distinction of generalized vs focal epilepsy is important in the choice of chronic AED therapy. Convulsive SE occurs with overt clinical signs, such as tonic, tonic-clonic, or clonic motor movements. Nonconvulsive status epilepticus (NCSE) occurs when either electrographic SE is associated with altered awareness without overt clinical signs, or altered awareness with subtle motor signs, such as minimal eyelid blinking. An EEG done at the time of SE (ictal EEG) can determine if the electrographic discharge is focal or generalized, demonstrate NCSE, or may also distinguish an epileptic event from a nonepileptic event (pseudoseizures). ${ }^{47,48}$ EEG has been recommended as routine in a Practice Parameter on the evaluation of the first nonfebrile seizure in children; SE was specifically excluded from the evidence examined. ${ }^{46}$

Evidence. Six class III studies ${ }^{29,31,34,40,49,50}$ report 413 EEG findings in 358 children who presented in SE and had an EEG. EEGs were obtained hours to days after the acute episode and $89.3 \pm 13.6 \%$ (range $66 \%$ to $100 \%$; median $92.9 \%$; $95 \%$ CI $78.3 \%$ to $100 \%$ ) were abnormal. Findings were described as generalized epileptiform features in $8 \%$, focal epileptiform features in 16\%, combined generalized and focal epileptiform features in 19\%, generalized slowing in $41 \%$, focal slowing in $6.3 \%$, electrocerebral inactivity in $1.9 \%$, and normal in $7.7 \%$. An epileptiform EEG was noted in $43.1 \%$ of these 358 children (table 3 ). One class III study $(\mathrm{n}=407)$ that focused on the prognosis of children with a first unprovoked seizure also had EEG data on 46 children with SE. ${ }^{49,50}$ This study found an abnormal EEG in $62 \%$ of children with SE, compared to $41 \%$ of children whose seizures were less than 30 minutes in duration.

Nonconvulsive status epilepticus: In adults, NCSE is present in $14 \%$ of patients in whom convul- 
Table 3 EEG findings in 358 children with status epilepticus

\begin{tabular}{lrcr}
\hline EEG findings & $\begin{array}{c}\text { No. of } \\
\text { patients }\end{array}$ & Percentage & Range, \% \\
\hline Normal & 32 & 7.7 & $0-34$ \\
Generalized slowing & 169 & 41.0 & $26-93$ \\
$\begin{array}{l}\text { Focal slowing } \\
\text { Epileptiform features, }\end{array}$ & 26 & 6.3 & $0-23$ \\
$\quad$ generalized only & 33 & 8.0 & $0-19$ \\
$\begin{array}{l}\text { Epileptiform features, } \\
\text { focal only }\end{array}$ & 66 & 16.0 & $0-47$ \\
$\begin{array}{l}\text { Epileptiform features, } \\
\text { generalized and focal }\end{array}$ & 79 & 19.1 & $0-42$ \\
$\begin{array}{l}\text { Electrocerebral inactivity } \\
\text { Total* }\end{array}$ & 8 & 1.9 & $0-3.9$ \\
\hline
\end{tabular}

* Refers to 413 EEG abnormalities reported in 358 patients from six class III studies (references 29, 31, 34, 40, 49, and 50).

sive $\mathrm{SE}$ is controlled but in whom consciousness remains impaired. ${ }^{51}$ Data are not available regarding the prevalence of NCSE after the control of convulsive SE in children or with other neurologic conditions (e.g., coma). A single study reported an $8 \%$ incidence of NCSE in a mixed population of children and adults with unexplained coma; data on children were not reported separately. ${ }^{52}$

Pseudostatus epilepticus: Pseudostatus epilepticus, defined as a nonepileptic event that mimics SE, may occur in children. ${ }^{53-55}$ In the only series of SE in children that reported on pseudostatus epilepticus, 6 of $29(21 \%)$ children admitted with convulsive SE had pseudoseizures (class III). ${ }^{53}$

Conclusions. Data from six class III studies revealed generalized or focal epileptiform activity in $43.1 \%$ of the EEGs done for SE. Abnormalities on EEG occur in $62 \%$ of children with SE compared to $41 \%$ of children with a first unprovoked seizure less than 30 minutes duration. Sufficient data on the prevalence of NCSE in children who presented with SE are not available. One small class III study reported that $21 \%$ of children initially thought to be in SE had pseudostatus.

Recommendations. 1. An EEG may be considered in a child presenting with new onset SE as it may determine whether there are focal or generalized abnormalities that may influence diagnostic and treatment decisions (Level C, class III evidence).

2. Although NCSE occurs in children who present with SE, there are insufficient data to support or refute recommendations regarding whether an EEG should be obtained to establish this diagnosis (Level U).

3. An EEG may be considered in a child presenting with SE if the diagnosis of pseudostatus epilepticus is suspected (Level C, class III evidence).

Neuroimaging. Should CT or MRI be performed in children with $\mathrm{SE}$ ? Neuroimaging studies were recommended based on specific clinical circumstances by the Practice Parameter for the evaluation of a first afebrile seizure in children. ${ }^{46}$ Emergent neuroimaging was recommended if there was a focal deficit that did not quickly resolve or if there was no return to baseline mental status after several hours, and nonurgent MRI should be seriously considered in any child with a seizure of partial (focal) onset with or without secondary generalization.

A previously published Practice Parameter on neuroimaging in the patient presenting with a seizure to the emergency department (1996) made no recommendations concerning neuroimaging in $\mathrm{SE}$, but suggested emergent neuroimaging when a serious structural lesion was suspected, especially when there were new onset focal deficits, persistent altered awareness, fever, recent trauma, history of cancer, history of anticoagulation, or a suspicion of AIDS. ${ }^{56}$ There have been no Parameters published on the use of neuroimaging in adult or pediatric cases of SE.

Neuroimaging should be done only after the child is stabilized and the SE has been controlled. Neuroimaging options include CT or MRI. MRI is more sensitive and specific than CT scanning, but CT is readily available on an emergency basis. CT and MRI may detect focal changes that may be transient, ${ }^{57}$ or secondary to a focal seizure (suggesting the origin of the focus), with MRI being more sensitive. Diffusion-weighted imaging (DWI) and apparent diffusion coefficient (ADC) changes have also been reported after SE in children and suggest cytotoxic and vasogenic edema. ${ }^{58-61}$ Progressive changes such as hippocampal atrophy/sclerosis or global atrophy have also been documented. ${ }^{62}$ Most childhood SE studies do not report neuroimaging findings specifically or were done before the advent of modern neuroimaging, but the diagnosis made in these studies supports the potential usefulness of neuroimaging.

Evidence. In 20 class III studies involving 1,951 children with SE (323 before the advent of neuroimaging), structural lesions were found in $7.8 \%$ (table E-1, on the Neurology Web site at www.neurology. org). Specific abnormalities included CNS malformation $(1.7 \%)$, trauma (1.6\%), stroke/hemorrhage $(0.9 \%)$, neurocutaneous disorder $(0.9 \%)$, tumor $(0.8 \%)$, infarct/vascular $(0.6 \%)$, hemorrhage $(0.4 \%)$, abscess/cerebritis $(0.4 \%)$, and arteriovenous malformation (AVM), hydrocephalus, or other $(0.2 \%$ each). These lesions are potentially diagnosable by neuroimaging.

Five class III studies $(\mathrm{n}=174)$ reported actual CT data. ${ }^{29,31,40,49,50}$ Of the CT scans done in children with $\mathrm{SE}$, a mean of $49 \%$ (range $29 \%$ to $70 \%$; median $53.4 \%$; $95 \%$ CI $32.2 \%$ to $66.7 \%$ ) were abnormal. Abnormalities included cerebral edema in $14.4 \%$, atrophy in $12.1 \%$, infection (meningitis/abscess/ cerebritis/granuloma) in $4.6 \%$, CNS dysplasia in $3.5 \%$ (tuberous sclerosis and Sturge Weber syndrome, 1 each), infarction in $2.9 \%$, tumor and hematoma in $2.3 \%$ each, $1.2 \%$ each in trauma and AVM, and calcifications in $0.6 \%$; an old deficit/no change was specified in $4.6 \% .{ }^{31}$ In 38 new-onset cases, CT 
was abnormal in $29 \%(\mathrm{n}=11)$, with dysplasia in 4 , atrophy, infarction, and infection in 2 each, and calcifications in 1.49,50 The timing after onset of SE when CT was done was not reported. This could affect interpretation of the presence of atrophy, which could be secondary to the episode of SE rather than to a preexisting abnormality. Under-representation of a cortical dysplasia as an etiology is likely due to the lower sensitivity of CT scanning in detecting such malformations.

In one small class III study MRI was done in 9 of 24 children with SE. ${ }^{42}$ Imaging findings were reported as normal in two and abnormal in seven of the nine children (78\%). ${ }^{42}$ Two each had atrophy, hydrocephalus, or cerebritis, and infarction occurred in one.

Conclusions. We assumed that neuroimaging was performed for clinical indications or the absence of a known etiology. The yield of lesions important for diagnosis and treatment was relatively high. Data from 20 class III studies found lesions likely detectable with neuroimaging in $7.8 \%$ of children, based on a denominator of all available subjects in the studies, thus these data represent an estimate of the minimal yield of these studies. Neuroimaging can identify structural causes for SE, especially to exclude the need for neurosurgical intervention in children with new onset SE without a prior history of epilepsy, or in those with persistent SE despite appropriate treatment.

Recommendations. 1 . Neuroimaging may be considered for the evaluation of the child with SE if there are clinical indications or if the etiology is unknown (Level C, class III evidence). If neuroimaging is done, it should only be done after the child is appropriately stabilized and the seizure activity controlled.

2. There is insufficient evidence to support or refute recommending routine neuroimaging (Level U).

Future research. 1. Prospective studies are needed to define what factors, or combination of factors, may precipitate SE in children.

2. Controlled prospective studies should be conducted to define the role for routine or selective laboratory investigations in the evaluation of children with SE. This should include studies of IEM, and specific serum toxicology levels, as a cause of SE in children with the diagnostic tests now available.

3. Controlled prospective blinded studies should be conducted to define the setting and timing for EEG done in the evaluation of children with SE, and to determine if postictal and unexpected ictal EEG findings have prognostic and treatment significance.

4. Controlled prospective studies with blinded assessments should examine the yield of neuroimaging, either routine or selective, in children with SE.

5. Prospective studies are needed to determine the frequency of NCSE after the control of convulsive SE in children, its etiology, and prognostic significance.
Mission statement. The Quality Standards Subcommittee (QSS) of the AAN seeks to develop scientifically sound, clinically relevant Practice Parameters for the practice of neurology. Practice Parameters are strategies for patient management that assist physicians in clinical decision making. A Practice Parameter is one or more specific recommendations based on analysis of evidence of a specific clinical problem. These might include diagnosis, symptoms, treatment, or procedure evaluation.

Disclaimer. This statement is provided as an educational service of the American Academy of Neurology. It is based on an assessment of current scientific and clinical information. It is not intended to include all possible proper methods of care for a particular neurologic problem or all legitimate criteria for choosing to use a specific procedure. Neither is it intended to exclude any reasonable alternative methodologies. The AAN recognizes that specific patient care decisions are the prerogative of the patient and the physician caring for the patient, based on all of the circumstances involved.

Conflict of interest statement. The American Academy of Neurology is committed to producing independent, critical and truthful clinical practice guidelines (CPGs). Significant efforts are made to minimize the potential for conflicts of interest to influence the recommendations of this CPG. To the extent possible, the AAN keeps separate those who have a financial stake in the success or failure of the products appraised in the CPGs and the developers of the guidelines. Conflict of interest forms were obtained from all authors and reviewed by an oversight committee prior to project initiation. AAN limits the participation of authors with substantial conflicts of interest. The AAN forbids commercial participation in, or funding of, guideline projects. Drafts of the guideline have been reviewed by at least three AAN committees, a network of neurologists, Neurology peer reviewers, and representatives from related fields. The AAN Guideline Author Conflict of Interest Policy can be viewed at www.aan.com.

\section{Appendix 1}

Quality Standards Subcommittee members: Jacqueline French, MD, FAAN (Co-Chair); Gary S. Gronseth, MD (Co-Chair); Charles E. Argoff, MD; Stephen Ashwal, MD, FAAN (ex-officio) (facilitator); Christopher Bever, Jr., MD, MBA, FAAN; John D. England, MD, FAAN; Gary M. Franklin, MD, MPH (ex-officio); Gary H. Friday, MD, MPH, FAAN; Larry B. Goldstein, MD, FAAN; Deborah Hirtz, MD (ex-officio); Robert G. Holloway, MD, MPH, FAAN; Donald J. Iverson, MD, FAAN; Leslie A. Morrison, MD; Clifford J. Schostal, MD; David J. Thurman, MD, MPH; William J. Weiner, MD, FAAN; Samuel Wiebe, MD.

CNS Practice Committee members: Carmela Tardo, MD (Chair); Bruce Cohen, MD (Vice-Chair); Diane K. Donley, MD; Bhuwan P. Garg, MD; Brian Grabert, MD; Michael Goldstein, MD; David Griesemer, MD; Edward Kovnar, MD; Augustin Legido, MD; Leslie Anne Morrison, MD; Ben Renfroe, MD; Shlomo Shinnar, MD; Gerald Silverboard, MD; Russell Snyder, MD; Dean Timmons, MD; William Turk, MD; Greg Yim, MD.
} 


\section{Appendix 2}

AAN evidence classification scheme for determining the yield of established diagnostic and screening tests.

Class I. A statistical, ${ }^{1}$ population-based ${ }^{2}$ sample of patients studied at a uniform point in time (usually early) during the course of the condition. All patients undergo the intervention of interest. The outcome, if not objective, ${ }^{5}$ is determined in an evaluation that is masked to the patients' clinical presentations.

Class II. A statistical, non-referral-clinic-based ${ }^{3}$ sample of patients studied at a uniform point in time (usually early) during the course of the condition. Most $(>80 \%)$ patients undergo the intervention of interest. The outcome, if not objective, ${ }^{5}$ is determined in an evaluation that is masked to the patients' clinical presentations.

Class III. A selected, referral-clinic-based ${ }^{4}$ sample of patients studied during the course of the condition. Some patients undergo the intervention of interest. The outcome, if not objective, ${ }^{5}$ is determined in an evaluation by someone other than the treating physician.

Class IV. Expert opinion, case reports or any study not meeting criteria for class I to III.

This is a classification scheme developed by the QSS for studies related to determining the yield of established diagnostic and screening tests or interventions and is appropriate only when the diagnostic accuracy of the test or intervention is known to be good. Additionally, the abnormality potentially identified by the screening intervention should be treatable or, should have important prognostic implications. This classification is different than others currently recommended by the QSS that have been published in recent parameters that relate to diagnostic, prognostic or therapeutic studies.
(1) Statistical sample: a complete (consecutive), random or systematic (e.g., every third patient) sample of the available population with the disease; (2) Population-based: The available population for the study consists of all patients within a defined geographic region; (3) Non-referral-clinicbased: The available population for the study consists of all patients presenting to a primary care setting with the condition; (4) Referral-clinicbased: The available population for the study consists of all patients referred to a tertiary care or specialty setting. These patients may have been selected for more severe or unusual forms of the condition and thus may be less representative; (5) Objective: An outcome measure that is very unlikely to be affected by an observers' expectations (e.g., determination of death, the presence of a mass on head CT, serum B12 assays).

\section{Appendix 3}

Classification of recommendations

$\mathrm{A}=$ Established as effective, ineffective, or harmful for the given condition in the specified population. (Level A rating requires at least two consistent Class I studies.)

$\mathrm{B}=$ Probably effective, ineffective, or harmful for the given condition in the specified population. (Level B rating requires at least one Class I study or at least two consistent Class II studies.)

$\mathrm{C}=$ Possibly effective, ineffective, or harmful for the given condition in the specified population. (Level C rating requires at least one Class II study or two consistent Class III studies.)

$\mathrm{U}=$ Data inadequate or conflicting; given current knowledge, test is unproven.

\section{Appendix 4}

Classification and laboratory data from class III studies of children presenting with status epilepticus (SE)*

\begin{tabular}{|c|c|c|c|c|c|c|c|c|c|c|c|}
\hline Reference & $\begin{array}{c}\text { No. of } \\
\text { patients }\end{array}$ & $\begin{array}{c}\text { Acute } \\
\text { symptomatic }\end{array}$ & $\begin{array}{c}\text { Remote } \\
\text { symptomatic }\end{array}$ & $\begin{array}{c}\text { Remote } \\
\text { symptomatic } \\
\text { with an } \\
\text { acute } \\
\text { precipitant }\end{array}$ & $\begin{array}{c}\text { Progressive } \\
\text { encephalopathy }\end{array}$ & Febrile & Cryptogenic & $\begin{array}{l}\text { Elec/ } \\
\mathrm{DeH}_{2} \mathrm{O}\end{array}$ & Met & Sepsis & $\begin{array}{c}\text { CNS } \\
\text { infection }\end{array}$ \\
\hline 26 & 239 & 63 & 40 & - & 10 & 67 & 59 & 18 & - & & 29 \\
\hline 27 & 218 & 87 & 72 & - & 3 & 50 & 6 & 25 & - & & 30 \\
\hline 28 & 189 & 26 & 86 & - & - & $\dagger$ & 77 & - & 8 & & 10 \\
\hline 29 & 153 & 71 & 59 & - & 2 & 21 & - & 5 & - & & 40 \\
\hline 30 & 139 & 56 & 9 & - & 10 & 57 & 7 & - & 14 & & 26 \\
\hline 31 & 114 & 17 & 66 & 7 & - & 16 & 8 & 5 & - & & 8 \\
\hline 32 & 112 & 25 & 69 & 1 & 7 & 5 & 5 & 1 & - & & 10 \\
\hline 4 & 193 & 45 & 45 & - & 11 & 46 & 46 & - & 4 & & 14 \\
\hline 33 & 90 & 24 & 33 & 6 & - & 27 & - & 2 & - & 1 & 18 \\
\hline 34 & 83 & 13 & 42 & - & 2 & - & 26 & 1 & - & 2 & 8 \\
\hline 35 & 65 & 13 & 10 & - & 3 & 24 & 15 & - & 3 & 1 & 8 \\
\hline 36 & 59 & 8 & 29 & 3 & - & 18 & 1 & 2 & - & & 2 \\
\hline 37 & 52 & 16 & 17 & - & 2 & 11 & 6 & 6 & - & 2 & 6 \\
\hline 38 & 37 & 14 & 16 & - & - & 6 & 1 & - & 3 & 1 & 4 \\
\hline 39 & 37 & 22 & 5 & - & 4 & 2 & 4 & - & 4 & & 8 \\
\hline 40 & 30 & 12 & 14 & - & - & 3 & 1 & 2 & 2 & 1 & 3 \\
\hline 41 & 25 & 11 & 8 & - & 1 & 3 & 2 & 4 & - & & 5 \\
\hline 42 & 24 & 6 & 9 & - & - & 1 & 8 & - & 1 & & 4 \\
\hline Total $\$$ & 1,859 & & & & & & & $\begin{array}{c}71 \\
(3.8 \%)\end{array}$ & $\begin{array}{c}39 \\
(2.1 \%)\end{array}$ & $\begin{array}{c}8 \\
(0.4 \%)\end{array}$ & $\begin{array}{c}233 \\
(12.8 \%)\end{array}$ \\
\hline $43 \S$ & 234 & 19 & 66 & - & 2 & 114 & 33 & - & - & & \\
\hline $\begin{array}{l}\mathrm{SE} \\
\text { classification, }\end{array}$ & 2,093 & $\begin{array}{c}548 \\
(26 \%)\end{array}$ & $\begin{array}{c}695 \\
(33 \%)\end{array}$ & $\begin{array}{c}17 \\
(1 \%)\end{array}$ & $\begin{array}{c}57 \\
(3 \%)\end{array}$ & $\begin{array}{c}471 \\
(22 \%)\end{array}$ & $\begin{array}{c}305 \\
(15 \%)\end{array}$ & - & - & & \\
\hline
\end{tabular}

Specific electrolyte abnormalities were noted as follows: $\mathrm{Na}(\mathrm{n}=28,1.5 \%) ; \mathrm{Ca}++(\mathrm{n}=9,0.5 \%)$; glucose $(\mathrm{n}=10,0.5 \%)$.

* Numbers in columns indicate the number of patients in each study who had an abnormal laboratory value for that test.

$\dagger$ Fever occurred in $35 \%$ of the overall group.

$\$$ Total number of abnormalities for each test given with percentage of total abnormalities.

§ Maegaki included here because it contained data on SE categories but did not have data for specific etiologies.

Elec/ $/ \mathrm{DeH}_{2} \mathrm{O}=$ electrolyte disorder or dehydration; $\mathrm{Met}=$ metabolic category, not otherwise specified; $\mathrm{Na}=$ sodium; $\mathrm{Ca}=$ calcium; Glu $=$ glucose . 


\section{References}

1. Gastaut H. Classification of status epilepticus. Adv Neurol 1983;34:1535.

2. Meldrum BS. Metabolic factors during prolonged seizures and their relation to nerve cell death. Adv Neurol 1983;34:261-275.

3. Meldrum B, Brierley JB. Prolonged epileptic seizures in primates: ischemic cell change and its relation to ictal physiological events. Arch Neurol 1973;28:10-17.

4. Maytal J, Shinnar S, Moshe SL, Alvarez LA. Low morbidity and mortality of status epilepticus in childhood. Pediatrics 1989;83:323-331. [Class III]

5. Dodson WE, DeLorenzo RJ, Pedley TA, Shinnar S, Treiman DM, Wannamaker BB. The treatment of convulsive status epilepticus: Recommendations of the Epilepsy Foundation of America's Working Group on Status Epilepticus. JAMA 1993;270:854-859.

6. Shorvon S. Status epilepticus: its clinical features and treatment in children and adults. Cambridge: Cambridge University Press, 1994.

7. Riviello JJ, Holmes GL. The treatment of status epilepticus. Semin Pediatr Neurol 2004;11:129-138.

8. Gastaut H. Clinical and electroencephalographic classification of epileptic seizures. Epilepsia 1970;11:102-113.

9. Commission on Classification and Terminology of the International League Against Epilepsy. Proposal for classification of epilepsies and epileptic syndromes. Epilepsia 1985;26:268-278.

10. Commission on Classification and Terminology of the International League Against Epilepsy. Proposal for revised classification of epilepsies and epileptic syndromes. Epilepsia 1989;30:389-399.

11. Hauser WA, Anderson VE, Loewenson RB, McRoberts SM. Seizure recurrence after a first unprovoked seizure. N Engl J Med 1982;307: $522-528$.

12. Sahin M, Menache C, Holmes GL, Riviello JJ. Outcome of severe refractory status epilepticus in children. Epilepsia 2001;42:1461-1467.

13. Commission on Epidemiology and Prognosis, International League Against Epilepsy. Guidelines for epidemiologic studies on epilepsy. Epilepsia 1993;34:592-596.

14. DeLorenzo RJ, Hauser WA, Towne AR, et al. A prospective, populationbased epidemiologic study of status epilepticus in Richmond, Virginia. Neurology 1996;46:1029-1035.

15. Coeytaux A, Jallon P, Galobardes B, Morabia A. Incidence of status epilepticus in French speaking Switzerland: (EPISTAR). Neurology 2000;55:693-697.

16. Hesdorffer DC, Logroscino G, Cascino G, Annegers JF, Hauser WA Incidence of status epilepticus in Rochester, Minnesota, 1965-1984. Neurology 1998;50:735-741.

17. Wu YW, Shek DW, Garcia PA, Zhao S, Johnston SC. Incidence and mortality of generalized convulsive status epilepticus in California. Neurology 2002;58:1070-1076.

18. Berg AT, Shinnar S, Levy SR, Testa FM. Status epilepticus in children with newly diagnosed epilepsy. Ann Neurol 1999;45:618-623.

19. Sillanpaa M, Shinnar S. Status epilepticus in a population-based cohort with childhood-onset epilepsy in Finland. Ann Neurol 2002;52:303-310.

20. Berg AT, Shinnar S, Testa FM, et al. Status epilepticus after the initial diagnosis of epilepsy in children. Neurology 2004;63:1027-1034.

21. Shinnar S, Pellock JM, Moshe SL, et al. In whom does status epilepticus occur: age-related differences in children. Epilepsia 1997;38:907-914.

22. Shinnar S, Maytal J, Krasnoff L, Moshe SL. Recurrent status epilepticus in children. Ann Neurol 1992;31:598-604.

23. Garr RE, Appleton RE, Robson WJ, Molyneaux EM. Children presenting with convulsions (including status epilepticus) to a paediatric accident and emergency department: an audit of a treatment protocol. Dev Med Child Neurol 1999;41:44-47.

24. Appleton R, Choonara I, Martland T, Phillips B, Scott R, Whitehouse W. The Status Epilepticus Working Party. The treatment of convulsive status epilepticus in children. Arch Dis Child 2000;83:415-419.

25. Appleton R, Martland T, Phillips B. Drug management for acute tonicclonic convulsions including convulsive status epilepticus in children. Cochrane Database Syst Rev 2002:CD001905.

26. Aicardi J, Chevrie JJ. Convulsive status epilepticus in infants and children: a study of 239 cases. Epilepsia 1970;11:187-197. [Class III]

27. Phillips SA, Shanahan RJ. Etiology and mortality of status epilepticus in children: a recent update. Arch Neurol 1989;46:74-76. [Class III]

28. Kang du C, Lee YM, Lee J, Kim HD, Coe C. Prognostic factors of status epilepticus in children. Yonsei Med J 2005;28:27-33. [Class III]

29. Lacroix J, Deal C, Gauthier M, Rousseau E, Farrell CA. Admissions to a pediatric intensive care unit for status epilepticus: a 10-year experience. Crit Care Med 1994;22:827-32. [Class III]

30. Tabarki B, Yacoub M, Selmi H, Oubich F, Barasaoui S, Essoussi AS Infantile status epilepticus in Tunisia: clinical, etiological and prognostic aspects. Seizure 2001;10:365-369. [Class III]

31. Dunn DW. Status epilepticus in children: etiology, clinical features, and outcome. J Child Neurol 1988;3:167-173. [Class III]

32. Scholtes FBJ, Renier WO, Meinardi H. Status epilepticus in children. Seizure 1996;5:177-184. [Class III]

33. Chin RFM, Verhulst L, Neville BGR, Peters MJ, Scott RC. Inappropriate emergency management of status epilepticus in children contrib- utes to need for intensive care. J Neurol Neurosurg Psychiatry 2004;75: 1584-1588. [Class III]

34. Karasalihoglu S, Oner N, Celtik C, Celik Y, Biner B, Utku U. Risk factors of status epilepticus in children. Pediatr Inter 2003;45:429-434. [Class III]

35. Eriksson KJ, Koivikko MJ. Status epilepticus in children: aetiology, treatment and outcome. Dev Med Child Neurol 1997;39:652-658. [Class III]

36. Mah JK, Mah MW. Pediatric status epilepticus: a perspective from Saudi Arabia. Pediatr Neurol 1999;20:364-369. [Class III]

37. Yager JY, Cheang M, Seshia SS. Status epilepticus in childhood. Can J Neurol Sci 1988;15:402-404. [Class III]

38. Garzon E, Fernandes RMF, Sakamoto AC. Analysis of clinical characteristics and risk factors for mortality in human status epilepticus. Seizure 2003;12:337-345. [Class III]

39. Kwong KL, Lee SL, Yung A, Wong VCN. Status epilepticus in 37 Chinese children: aetiology and outcome. J Paediatr Child Health 1995; 31:395-398. [Class III]

40. Gulati S, Kalra V, Sridhar MR. Status epilepticus in Indian children in a tertiary care center. Indian J Pediatr 2005;72:105-108. [Class III]

41. Kwong KL, Chang K, Lam SY. Features predicting adverse outcomes of status epilepticus in childhood. Hong Kong Med J 2004;10:156-159. [Class III]

42. Ibrahim SH, Yezdan MA, Nizami SQ. Status epilepticus in children: a five-year experience at Aga Khan University Hospital. J Pak Med Assoc 2003;53:597-599. [Class III]

43. Maegaki Y, Kurozawa Y, Hanaki K, Ohno K. Risk factors for fatality and neurological sequelae after status epilepticus in children. Neuropediatrics 2005;36:186-192. [Class III]

44. Chin RF, Neville BG, Scott RC. Meningitis is a common cause of convulsive status epilepticus with fever. Arch Dis Child 2005;90:66-69. [Class III]

45. Maytal J, Novak G, Ascher C, Bienkowski R. Status epilepticus in children with epilepsy: the role of antiepileptic drug levels in prevention. Pediatrics 1996;98:1119-1121. [Class II]

46. Hirtz D, Ashwal S, Berg A, et al. Practice parameter: Evaluating a first non-febrile seizure in children Neurology 2000;55:616-623.

47. Privitera MD, Strawsurg RH. Electroencephalographic monitoring in the emergency department. Emerg Med Clin North Am 1994;12:1089-1101.

48. Thomas P. Status epileptics: Indications for emergency EEG. Neurophysiol Clin 1997;27:398-405.

49. Shinnar S, Kang H, Berg AT, Goldensohn ES, Hauser WA, Moshe SL. EEG abnormalities in children with a first unprovoked seizure. Epilepsia 1994;35:471-476. [Class III]

50. Shinnar S, Berg AT, Moshe SL, et al. The risk of seizure recurrence following a first unprovoked afebrile seizure in childhood: An extended follow-up. Pediatrics 1996;98:216-225. [Class III]

51. DeLorenzo RJ, Waterhouse EJ, Towne AR, et al. Persistent nonconvulsive status epilepticus after the control of convulsive status epilepticus. Epilepsia 1998;39:833-840.

52. Towne AR, Waterhouse EJ, Boggs JG, et al. Prevalence of nonconvulsive status epilepticus in comatose patients. Neurology 2000;54:340-345.

53. Pakalnis A, Paolicchi J, Gilles E. Psychogenic status epilepticus in children: Psychiatric and other risk factors. Neurology 2000;54:969970. [Class III]

54. Tuxhorn IEB, Fischbach HS. Pseudostatus epilepticus in childhood Pediatr Neurol 2002;27:407-409.

55. Papavasiliou A, Vassaliki N, Paraskevolakos E, Kotsalis Ch, Bazigou $\mathrm{H}$, Bardani I. Psychogenic status epilepticus in children. Epilepsy Behav 2004;5:539-546.

56. Greenberg MK, Barsan WG, Starkman S. Practice parameter: neuroimaging on the emergency patient presenting with seizure-summary statement. Neurology 1996;47:26-32.

57. Kramer RE, Luders H, Lesser RP, et al. Transient focal abnormalities of neuroimaging studies during focal status epilepticus. Epilepsia 1987; 28:528-532.

58. Lansberg MG, O’Brien MW, Norbash AM, Moseley ME, Morrell M, Albers GW. MRI abnormalities associated with partial status epilepticus. Neurology 1999;52:1021-1027.

59. Kim J, Chung JI, Yoon PH, et al. Transient MR signal changes in patients with generalized tonic clonic seizure or status epilepticus: peri ictal diffusion-weighted imaging. AJNR Am J Neuroradiol 2001;22: 1149-1160.

60. Senn P, Lovblad KO, Zutter D, et al. Changes on diffusion-weighted MRI with focal motor status epilepticus: case report. Neuroradiology 2003;45:246-249.

61. Scott RC, Gadian DG, King MD, Chong WK, Cox TC, Neville BGR. Magnetic resonance imaging findings within 5 days of status epilepticus in childhood. Brain 2002;125:1951-1959.

62. Perez ER, Maeder P, Villemure KM, Vischer VC, Villemure JG, Deonna $\mathrm{T}$. Acquired hippocampal damage after temporal lobe seizures in 2 infants. Ann Neurol 2000;48:384-387.

63. Fujiwara T, Ishida S, Miyakoshi M, et al. Status epilepticus in childhood: a retrospective study of initial convulsive status and subsequent epilepsies. Folia Psychiatr Neurol Jpn 1979;33:337-344. [Class III]

64. Vigevano F, DiCapua M, Fusco L, Bertini E, Maccagnani F. Status epilepticus in infancy and childhood. J Pediatr Neurosci 1985;1:101112. [Class III] 


\title{
Neurology
}

\author{
Practice Parameter: Diagnostic assessment of the child with status epilepticus (an \\ evidence-based review): Report of the Quality Standards Subcommittee of the \\ American Academy of Neurology and the Practice Committee of the Child Neurology \\ Society \\ J. J. Riviello, Jr, S. Ashwal, D. Hirtz, et al. \\ Neurology 2006;67;1542-1550 \\ DOI 10.1212/01.wnl.0000243197.05519.3d
}

This information is current as of November 13, 2006

\section{Updated Information \& Services}

Supplementary Material

References

Citations

Permissions \& Licensing

Reprints including high resolution figures, can be found at: http://n.neurology.org/content/67/9/1542.full

Supplementary material can be found at: http://n.neurology.org/content/suppl/2006/11/04/67.9.1542.DC1 http://n.neurology.org/content/supp1/2007/04/24/67.9.1542.DC2

This article cites 54 articles, 11 of which you can access for free at: http://n.neurology.org/content/67/9/1542.full\#ref-list-1

This article has been cited by 8 HighWire-hosted articles: http://n.neurology.org/content/67/9/1542.full\#\#otherarticles

Information about reproducing this article in parts (figures,tables) or in its entirety can be found online at:

http://www.neurology.org/about/about_the_journal\#permissions

Information about ordering reprints can be found online:

http://n.neurology.org/subscribers/advertise

Neurology ${ }^{\circledR}$ is the official journal of the American Academy of Neurology. Published continuously since 1951, it is now a weekly with 48 issues per year. Copyright . All rights reserved. Print ISSN: 0028-3878. Online ISSN: 1526-632X.

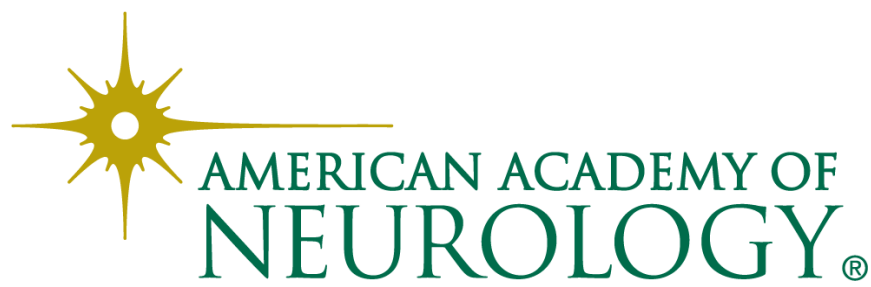

